\title{
Does one design fit them all? Study of drivers of co-creation interest along different consumer segments
}

\author{
Shahab Zare ${ }^{1}$, Debora Bettiga ${ }^{2}$, Lucio Lamberti ${ }^{3}$ \\ ${ }^{1}$ Institute of Management, Scuola Superiore Sant'Anna, Piazza Martiri della Libertà 33, \\ 56127, Pisa, Italy \\ ${ }^{23}$ Department. of Management, Economics and Industrial Engineering, Politecnico di Milano, \\ Via Lambruschini 4b, 20156, Milan, Italy \\ ${ }^{2}$ Corresponding author: e-mail: debora.bettiga@polimi.it; phone: +39 0223992816
}

\begin{abstract}
Co-creation with consumers is increasingly attracting the interest of companies, as a rich source of innovation and value generation. However, the triggers of consumer's interest toward co-creation and how they change among different consumer segments are still unclear. This article explores this issue, by investigating (i) the product-related drivers of interest, namely the product typology, product knowledge and prior cocreation experience, and (ii) the consumer-related drivers of interest, namely motivations and inhibitors to co-create. The work further investigates if motivations and inhibitors as well as the preference toward a co-creation tool change among different consumer segments. Findings from 509 participants in a survey study reveal that both personal and product-related drivers affect the interest toward co-creation projects: specifically, monetary and personal benefits have the greatest influence on co-creation interest as well as prior co-creation experience and deep product knowledge. Further, motivations, inhibitors and co-creation tools preference vary according to the consumer segment. This work underlines the importance of delivering tangible benefits to attract consumers in co-creation projects and to design the activity according to the consumer typology the firm wants to attract.
\end{abstract}

Keywords: co-creation interest; drivers of co-creation; consumer segments; motivations and inhibitors; co-creation tools; 


\section{Introduction}

The involvement of consumers, as not merely passive audience but as co-inventors and codevelopers with firms, is an emerging phenomenon in the market (Fernandes \& Remelhe, 2016; Prahalad \& Ramaswamy, 2004b) and firms need to know how to and which consumers involve in this conjoint process. The more firms know about the needs of consumers, the more they can involve them in firm activities, the more they can offer sustainable goods and services which would be easier embraced by the market. The value offer, once entirely developed by the firm, is going to be increasingly defined by the experience of customers and their interactions with companies (Prahalad \& Ramaswamy, 2004b). This implies that firms need to know which consumers are more interested, but also more efficient and effective, in co-creation activities. In other words, which consumers can provide most value to the firm. Different subjects may be interested in co-creation activities: from consumers with very knowledgeable background within a specific industry (von Hippel, 2005; Von Hippel, 2007), to individuals trying to satisfy a need for specific products, passing through loyal customers who have strong relationships with a brand or company and like to help in product development (Fuller, Kurt, \& Hopper, 2008). Some consumers seem to have a positive inclination toward co-creation activities (Hoyer, Chandy, Dorotic, Krafft, \& Singh, 2010), providing better outcomes in terms of innovative ideas (Taghizadeh, Rahman \& Marimuthu, 2018), effective participation in the product development and even diffusion of the innovation among other consumers. Thus, targeting them can result in a source of opportunities and efficiency for companies. A wrong choice, on the opposite, can be detrimental and potentially lead to company image and reputation decline, as some unsuccessful cases of co-creation shown, such as the complaints and dissatisfaction generated by the "SPAR bag design contest” (Gebauer, Füller, \& Pezzei, 2013) or by the Henkel packaging design contest, resulted in negative ideas gathering. Thus, it seems desirable for firms to attract consumer 
segments able to provide real value in the co-creation process. But how can firms attract these consumers?

Prior research has individuated some universal motivations and inhibitors to cocreation participation. Some individuals participate in the co-creation activity to satisfy their own personal needs (Heidenreich \& Handrich, 2015) such as lead users who invest time and energy in co-creation in order to maximize usage satisfaction in future (Schuhmacher \& Kuester, 2012; von Hippel, 1986). Some others engage in co-creation activities due to external benefits they might get, as those consumers who seek monetary rewards or fame (Johann Füller, 2010). On the other hand, there are some inhibitors that need to be minimized, such as the cost of time spent in learning, logistic costs but even the psychological cost of project failure or the risk of idea appropriation by other consumers or by the firm. However, even if it has been proved that an accurate combination of these motivators and a proper reduction of inhibitors would stimulate consumers to involve in co-creation (Hoyer et al., 2010), a lack of research is evident on how they change among different segments of consumers and which ones, if any, are more critical in fire up consumers interest. A clear understanding of these relationships is a clear need for firms, in order to develop successful and well-tailored co-creation activities. Thus, the first aim of our research is to investigate the impact of different personality traits, characterizing critical consumer segments, on motivations and inhibitors to co-create.

Above motivations and constraints, the way the co-creations activity is deployed may influence consumer participations. Each consumer segment may have a positive attitude toward specific co-creation methods and tools but not others. Some tools, such as workshops (von Hippel, 2005; Von Hippel, 2007) need more time and energy but do not require IT knowledge, some others, such as ideation contests (Piller \& Walcher, 2006), are technically complex and require people to own the related technical knowledge for performing the tasks 
(Aarikka-Stenroos \& Jaakkola, 2012). Firms need to provide an attractive environment to enable easy and efficient co-creation participation by consumers, thus the understanding of the right co-creation tool to provide is critical for the success of such initiatives. Despite the relevance of the issue, prior research did not analyze this topic, thus our second aim is to shed lights on the relationships between consumer segments and co-creation tool preferences.

Finally, product category matters, especially for co-creators. Consumers co-create in product categories in which they feel expert and for brands they trust (Füller, Hutter, \& Faullant, 2011). Nonetheless, strong brands could disincentive co-creation, due to the loss of psychological and social benefits embedded in the brand own personality (Etgar, 2008). However, consumers could also be interested in co-creation activities for products of the same category, independently from the brand (Füller et al., 2011). For instance, cars lovers are more interested in the development of car parts than other products. Overall, co-creation is more suitable in product categories in which differentiation plays an important role and represents a source of value for consumers (Etgar, 2008). For instance, in software development co-creation is a synonymous of high quality as consumers often possess high technical skills and are experts of the specific product category thus can improve the final offer (Füller, Mühlbacher, Matzler, \& Jawecki, 2009). The importance of the product category is affected by the levels of perceived empowerment and enjoyment as well (Füller et al., 2009), which determine consumers participation in new product development projects and vary according to the participants' product involvement and creativity. Prior research focused on a specific industry or product category, such as sports industry (Fredberg \& Piller, 2011) or computer games (Prugl \& Schreier, 2006). However, with the growth of the phenomenon across industries, there is a need to understand how different domains affect the consumer involvement. Hence, our third aim is to assess if product specific factors, namely product 
typology, product-specific knowledge and prior co-creation affect consumer interest in cocreation.

The article is organized as follow: the subsequent section analyzes prior research on the topic and presents our hypotheses as well as the conceptual model to be investigated; next methodology and results are presented; the paper follows with a discussion of research and implications. Finally, it presents conclusions and provides suggestions for future research.

\section{Literature review and hypotheses development}

Figure 1 presents our conceptual framework, which depicts the determinants of co-creation interest. Specifically, we concentrate on one side on individual drivers of interest where we depict the role of personal traits as determinants of consumer motivations and inhibitors and of co-creation tool preference. On the other side, we propose product-related sources of interest: product typology, product knowledge and prior co-creation experience for the specific product. In subsequent sections, we elaborate on each of these key drivers. 


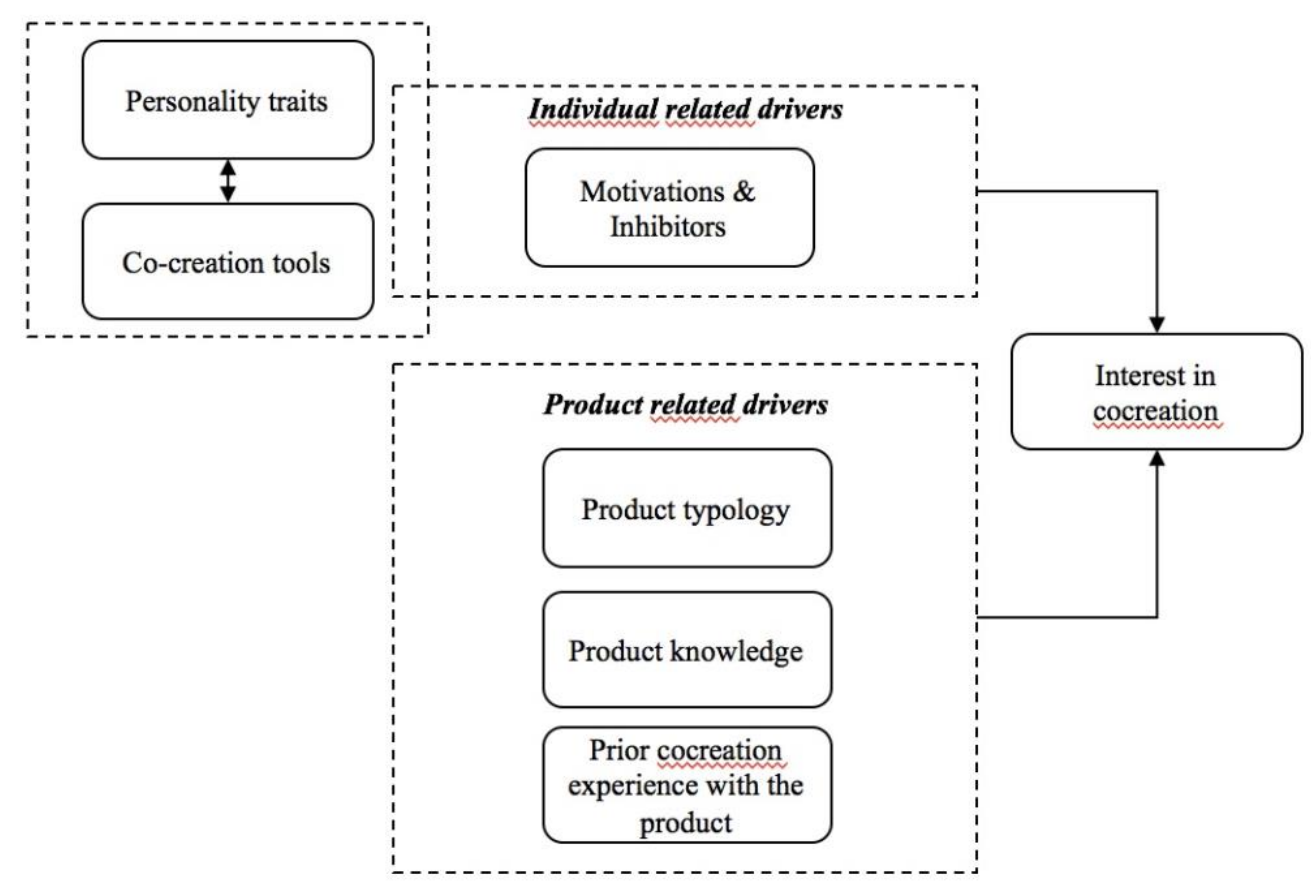

\section{Motivations}

A combination of different motivations is needed to stimulate consumers in participating in co-creation activities (Füller, 2010; Hoyer et al., 2010).

\section{Learning motivations}

Learning motivations refer to the extent a consumer expects to learn about products or services and their underlying technology, by participating in co-creation activities (Blumler \& Katz, 1974; Nambisan \& Baron, 2007). In communities of virtual co-creation, participants receive information, support, but also feedbacks and generate a dialogue together with other consumers (Bugshan, 2015; Haythornthwaite, 2008). The knowledge generated by consumers and by the co-creation process itself could be shared among participants and with the firm. The exchange of information, the deriving skills improvement and new solutions to unanswered topics are all example of learning (Füller, 2010; Nambisan \& Baron, 2007; 
Wasko \& Faraj, 2000). Thus, we assume that learning motivations are a relevant trigger of interest in co-creation:

HP1.1: Learning motivations have a positive influence on interest to co-create

\section{Social motivations}

As exchange of knowledge, also the development of social relationships occurs between the community of participants and the firm during co-creation activities, enabling the strengthening of ties between the firm and consumers or among consumers and the creation of personal and social networks (Hoyer et al., 2010; Nambisan \& Baron, 2007). Social benefits, such as strong social identity and sense of belongingness to the community can strengthen participation in co-creation activities (Bugshan, 2015; Muniz \& O’Guinn, 2001; Nambisan \& Baron, 2007). Thus:

HP1.2: Social motivations have a positive influence on interest to co-create

\section{Personal motivations}

Consumers can derive personal benefits such as fame, reputation in network of participants, status and authority while participating in co-creation activities. Some companies incentivize consumers to participate in co-creation by offering them status and recognition for their prospective rich ideas or suggestions, such as “Amazon's top 100 reviewers' recognition (Hoyer et al., 2010). Pride of authorship and getting credit for product success are kinds of incentives that motivate consumers to engage in these activities (Muniz \& O'Guinn, 2001; Nambisan \& Baron, 2007). Following:

HP1.3: Personal motivations have a positive influence on interest to co-create 


\section{Hedonic motivations}

Hedonic motivations refer to the enjoyment, fun and pleasure that a consumer perceives for participating in co-creation (Paulini, Maher, \& Murty, 2014). Talking about beloved product brings enjoyment by itself, but participating in a problem-solving task related to these products derives much more hedonic experiences to the consumers (Muniz \& O'Guinn, 2001; Nambisan \& Baron, 2007). The mere co-creation activity, regardless the product, could be stimulating as well. The consumer can engage in product and service development for its own sake because he finds the activity playful and entertaining (Füller, 2010). Consequently:

HP1.4: Hedonic motivations have a positive influence on interest to co-create

\section{Monetary motivations}

Firms may give some monetary incentives to the consumers for participating in the cocreation activity centered on their business. Monetary incentives could be in the form of financial reward, product giveaways, lotteries and coupons. The dark side of proposing monetary incentives is that some consumers might engage in the activity just because of benefits they might receive while they do not have any underlying knowledge (Füller, 2010). Thus:

HP1.5: Monetary motivations have a positive influence on interest to co-create

\section{Inhibitors}

Despite literature on inhibitors is less developed than the one investigating motivations, some studies tried to shed lights on constraints to co-creation participation (Aarikka-Stenroos \& Jaakkola, 2012; Etgar, 2008; Hoyer et al., 2010; Kankanhalli, Tan, \& Wei, 2005). 


\section{Time and energy inhibitor}

Co-creators need to devote their time and energy to participate in co-creation activities while the result of their participation is ambiguous. The more a co-creation process gets complex or technical, the higher effort consumers need to deliver in order to perform the task. These costs can prevent consumers to involve in co-creation. Companies need to minimize these foregone opportunities if they want to increase the chance to attract consumers in their co-creation projects (Aarikka-Stenroos \& Jaakkola, 2012; Hoyer et al., 2010; Kankanhalli et al., 2005). Hence:

HP1.6: Time and energy inhibitors have a negative influence on interest to co-create

\section{Risk of discredit}

The ambiguity of results translates co-creation in a social risky activity. The major hinders from this side are the risks of losing intellectual property rights, being deceived by the firms or even getting mocked by other people for own ideas and comments. Consumers can also be afraid of losing power and their unique status within the community (Aarikka-Stenroos \& Jaakkola, 2012; Kankanhalli et al., 2005). As these risks can prevent consumers from participating in co-creation activities, firms need to minimize them and create a trustworthy environment. Following:

HP1.7: Risks of discredit have a negative influence on interest to co-create

\section{Co-creator personality traits}

Each consumer's singularity affects the way co-creation happens (Prahalad \& Ramaswamy, 2004a). Some consumers have more familiarity related to a particular product and its related technology while others are more knowledgeable about the market environment. Prior research has identified, based on a specific set of personality traits, some desirable typologies 
of consumers to be included in co-creation activity: innovators, market mavens and emergent nature (Hoyer et al., 2010; Parasuraman, 2000; Tsikriktsis, 2004). Consumers with a positive orientation to new technologies (Parasuraman, 2000; Tsikriktsis, 2004) have been identified as desirable segments to be involved in co-creation as well.

\section{Innovators}

Scholars have remarked different definition for individual innovativeness. On a behavioral perspective, it has been studied on the basis of new product adoption behavior as "actualized innovativeness" (Hirschman, 1980) or through the number and timing of adoptions (Schreier \& Prügl, 2008). On a personality perspective, the innate individual innovativeness has been used as a proxy of consumer's innovativeness level (Kirton, 1976). This definition reflects the general character of a consumer and does not cover the "domain-specific innovativeness" which is related to a specific product or category of products (Moore, G. A., \& McKenna, 1999). Innovative consumers are the ones that try new products on the market (Rogers, 2010) out of curiosity, dissatisfaction with the current offer or for status enhancement. The most proactive innovators can be individuated in the few early and active participants in a new field who build innovative products for themselves or for other closed people, and eventually create a lifestyle around them (Shah, 2000). Innovators are dynamic consumers, bringing periodic revolutionary change in the market and having low self-doubt when generating ideas (Kirton, 1976). Thus, we assume that innovators have stronger learning and hedonic motivations derived from their curiosity and willingness to try new products and social and personal motivations connected to their social status and imagine of pioneers in their community. Monetary motivations seem a peculiar trigger as well, as innovators have the tendency to create business around their own innovations (Shah, 2000). For what concern inhibitors, we assume that innovators perceive lower risk and effort constraints, thanks to their confidence and risk-taking approach to new technologies. Thus, we assume that: 
HP2.1: Innovators perceive higher motivations to co-create

HP2.1: Innovators perceive lower risk and effort inhibitors to co-create

\section{Market Mavens}

Market Maven are those individuals with market expertise that share their knowledge by initiating discussions with other consumers and are influential on their buying decisions (Feick \& Price, 1987). Differently from opinion leaders, market mavens' expertise and knowledge are not product-centric but related to the market. They have a tendency to acquire and transmit information about the marketplace (Feick \& Price, 1987) due to their selfobligation to stay informed and knowledgeable (Kassarjian, 1981), to their interest into purchasing goods (Slama \& Tashchian, 1985) or with the aim to build relationship with other people within their social groups (Atkin, 1972; Levy, 1978) Furthermore, some individuals grasp information about the marketplace and share it with other consumers with the hope of receiving rewards or information they have no access to, making the exchange fruitful for both parts (Sieber, 1974). The pleasure of shopping is another peculiar characteristic of market mavens, explaining their high interest in general marketplace (Feick \& Price, 1987). Therefore, we assume that learning and social motivations have higher relevance to this consumers' typology because of their information seeking and sharing attitude. Pleasurable experiences of shopping bespeak about the importance of hedonic motivations to these consumers, while monetary and personal motivations seem to born from the likelihood to exchange information with other people or entities and seeking monetary rewards. As a result of their time-consuming activity of collecting and sharing information, we assume that time and effort constraints will be less relevant for this consumer typology. Sharing some characteristics of early adopters, such as high self-confidence, we assume that market mavens also perceive a lower risk of discredit compared to ordinary consumers. Thus: 
HP3.1: Market mavens perceive higher motivations to co-create

HP3.2: Market mavens perceive lower risk and effort inhibitors to co-create

\section{Emergent nature}

Emergent nature are those consumers who are able to imagine and visualize the concepts and ideas, which might be useful and prospering for the marketplace in the future. These users are described as optimistic, creative, with a high ability of rational thinking and visualization and open to experience new products (Hoffman, Kopalle, \& Novak, 2009). The consumers with an emergent nature trait are supposed to be more influential while proposing an idea (for example suggesting a nifty concept) rather than other consumers (Hoffman et al., 2009). In their empirical study, Hoffman et al. (2009)concluded that product concepts developed by users with an emergent nature have higher purchase probability and tend to be better on the utilitarian features. We assume that the self-confidence characterizing this consumer typology, their openness to new experiences and products, similar to market mavens, make them less concerned by risk of discredit in co-creation. Their great ability of rational thinking, making let us assume they are less concerned about participation effort as well (Hoffman et al., 2009). Thus:

H4.1: Emergent nature consumers perceive higher motivations to co-create

H4.2: Emergent nature consumers perceive lower risk and effort inhibitors to co-create

\section{Technology enthusiast consumers}

We define technology enthusiast consumers as those individuals with a high level of optimism and innovativeness toward new technologies. Optimism is connected with a positive view of technology, including individual beliefs of control, flexibility and efficiency, while innovativeness is the tendency to keep up-to-date on new technologies (Parasuraman, 2000). 
This tendency requires seeking new information and updating one's knowledge on a regular basis (Parasuraman, 2000). We can thus assume that learning benefits and personal ones are highly associated with this consumer category. The hedonic side of technology usage is also important (Bettiga \& Lamberti, 2017). Being optimist in technology triggers the belief of having an increased control, efficiency and flexibility in daily lives (Parasuraman, 2000) and can be related to a lower perception of discredit risk. Time and effort inhibitors could have lower importance as well for this typology of consumers, due to their perceived efficiency and flexibility in performing tasks (Parasuraman, 2000; Tsikriktsis, 2004). Consequently:

HP5.1: Technology enthusiastic consumers perceive higher motivations to co-create.

HP5.2: Technology enthusiastic consumers perceive lower risk and effort inhibitors to cocreate

\section{Co-creation tools}

Firms provide different instruments to enable consumer participation: community for customer co-creation (Füller et al., 2008), toolkits for user innovation (von Hippel \& Katz, 2002), ideation contest (Piller \& Walcher, 2006) and lead user workshops (von Hippel, 2005; Von Hippel, 2007). Mass customization, user-generated content, mass collaboration and open source are other mechanisms that consumers can use for co-creating value with companies (Roser, Samson, Cruz-Valdivieso, \& Humphreys, 2009).

\section{Virtual communities}

A virtual community is a network of people who have common interests, initiate discussions about a topic and help each other by participating in the discussion. The community is not restricted to any geographical area and enables the development of social relations among users (Muniz \& O’Guinn, 2001). Shared consciousness, common rituals and sense of a moral responsibility characterize a virtual community (McAlexander, Schouten, \& Koenig, 2002). 
Benefits of participating in a community can be the enjoyment, fun and satisfaction emerging through involvement in the "discussing and responding" stream (Lerner \& Tirole, 2001). Blackberry, Lenovo Thinkpad, Starbucks and many other brands hold a virtual community to involve their customers into the co-creation process, sharing their knowledge, helping each other to experience the utmost satisfaction usage of the product or services (Hoyer et al., 2010). Market mavens, due to their willingness to share knowledge and information by initiating discussions with other consumers can find virtual communities an optimal ecosystem for co-creation. Technology enthusiastic, being up-to-date and willing to try the newest technologies, seem to have a tendency toward participating in virtual communities and to be moderators or administrators of those communities. Generalizing, all consumers with a tendency toward social relations can be attracted by virtual communities for co-creation.

\section{Toolkits for user innovation}

The aim of toolkits is to outsource innovation and design activities, which are traditionally in the hands of the firms, to the consumers. Toolkits or configurators derive benefits both for the consumer and the firms. Instead of transmitting information on knowledge and needs between the two sides in traditional (and time-consuming) ways, toolkits are designed to save time by enabling innovation through trial-and-error activities in a cost-efficient way (Summary \& Reading, 2002; Von Hippel, 2001; von Hippel \& Katz, 2002). They give the consumers the ability to promote their product on the basis of their unique needs (Summary \& Reading, 2002; von Hippel \& Katz, 2002). Toolkits connect two information flows: solution information provided by the firm for the product development process and need information hold by the consumers (Von Hippel, 2001). Some toolkits are appropriate for the users who have technical field knowledge while some other toolkits are easy to handle for the majority of consumers in a marketplace. For instance, Coco Myles (www.cocomyles.com) is providing a toolkit for designing tailored dresses which need user designing knowledge but provide also 
the possibility to develop simplistic designs for users without high design knowledge. Toolkits for user innovation can be more attractive for individuals, such as innovators, that already perform trial and error activities to improve a product or a service feature (Von Hippel, 2001) in response to a dissatisfaction with the current offer or a desire for personalization. Emergent nature consumers could be willing to use this tool as well, having a propensity to verbal processing and visual processing. The positive attitude toward computer and IT of technology enthusiastic consumers, can spur them in using toolkits in order to reach the maximum satisfaction from their products.

\section{Ideation contests}

The main purpose of ideation contests is to produce novel ideas. Firms that are seeking a solution to a problem can ask final consumers to propose ideas to solve that problem. Best ideas usually receive prizes or rewards (Piller, Vossen, \& Ihl, 2012; Piller \& Walcher, 2006). Firms adopt different strategies to allocate prizes to the best solutions: they can offer monetary rewards or personal benefits such as pride of authorship, participation in product success and recognition (Franke \& Shah, 2011; Johann Füller, 2010; Piller et al., 2012). Participants are not only competitors. They eventually read each other's ideas, give comments and evaluations, thus developing social relationships. Ideation contests work better when participants are accommodating and helping each other but also, conversely, when there is no cooperative relationship at all (Bullinger, Neyer, Rass, \& Moeslein, 2010; Hutter, Hautz, Füller, Mueller, \& Matzler, 2011; Piller et al., 2012). BMW, Boeing and InnoCentive are examples of companies using ideation contests (Piller et al., 2012; Piller \& Walcher, 2006). Ideation contests can be particularly attractive for innovators, individuals with the ability to make a revolutionary change in a product concept and perceiving low self-doubt while generating ideas and concepts (Kirton, 1976). Also technology enthusiastic can be attracted 
by this form of participation, thanks to their leadership and pioneer attitude that may spur them in competing with other consumers.

\section{Workshops}

Through workshops, consumers are invited to join a group of people working together with company representatives on product or service development. The company seeks to extract innovative ideas from these subjects. Participants usually work in small groups primarily and then they gather together to design final concepts which suit company needs, finally assessing the concepts and ideas in terms of feasibility, attractiveness to the market and management priorities (Lilien, Morrison, Searls, Sonnack, \& Hippel, 2002). Usually, workshops last for two or three days, consist of around 15 people by which a third of them are generally the company's representatives (Hienerth, Poetz, \& von Hippel, 2007). LEGO and 3M are adopting this method for product and service development (Hienerth, Lettl, \& Keinz, 2013; Hienerth et al., 2007). Consumers with social attitude, willingness to share knowledge and interact with a group of consumers, such as market mavens, can be particularly apt to participate in workshops. Also consumer with a high product-centric knowledge or technical capabilities, as technology optimistic, can find workshop a favorable environment. Emergent nature consumers, apt to experientially explore and rationally investigate alternatives in product and service development fields can be of great help in workshops, due to their analytical capabilities (Hoffman et al., 2009).

According to the distinctive personal traits of each co-creator typology and the inherent characteristics of co-creation tools we assume:

HP6.1: Innovators have a preference for toolkits for user innovation and ideation contests

HP6.2: Market maven have a preference for co-creation community and user workshops 
HP6.3: Emergent nature have a positive inclination toward all co-creation tools

HP6.4: Technology enthusiastic have a positive inclination toward to all co-creation tools

\section{Product-related drivers}

\section{Product typology}

Different industries have been subjects of research on co-creation. For instance, Fredberg \& Piller (2011) investigated the effect of tie strength on innovation in the sports industry. Prugl \& Schreier (2006) studied the process of using toolkits for user innovation by lead users and ordinary users in computer games industry. Barilla Company has been used as a case study of customer co-creation at the front end innovation (Martini, Massa, \& Testa, 2014). Knowledge-intensive business services have been analyzed by Aarikka-Stenroos \& Jaakkola (2012). However, these studies have observed co-creation activities in specific industries not analyzing the impact of industry context on co-creation activities design and effectiveness. Thus, we investigated how the product typology affects co-creation interest among consumers. We selected three industries, which differ in underlying product characteristics: music industry, health \& fitness industry and additive manufacturing industry. We hypothesize that:

HP7. Product typology affects co-creation interest

\section{Product knowledge}

Consumer's product-related knowledge is traditionally studied in terms of the extent of knowledge an individual possesses (i.e. expertise) and the locus of knowledge evaluation occurring. The latter classifies into two sub-categories of objective knowledge and subjective knowledge (Alba \& Hutchinson, 1987). Objective knowledge occurs when an impartial third party evaluates the information that an individual carries with himself while the subjective 
knowledge implies the self-evaluation of knowledge regarding a product usage (Cordell, 1997). What is more relevant in spurring co-creation interest is subjective knowledge, thus capabilities and information a consumer believes to hold. However, an increasing level of objective product knowledge will result to better acquiring, visualizing, processing and developing of that information into reality while comprehending more complex productrelated challenges (Schreier \& Prügl, 2008), thus delivering a better co-creation outcome. Therefore, we hypothesize that:

HP8. Product knowledge has a positive impact on co-creation interest

\section{Prior co-creation experience}

Co-creation activities and their related "benefit-cost" outcomes shape an individual's decision toward engagement in such initiatives. Meanwhile, individual decisions are shaped by prior experiences as well and their related outcomes. Prior experience shown to be an important indicator for the future intention and behavior of an individual (Bagozzi, 1981) as the ambiguity and risks of approaching a task is reduced if the task has already been performed in the past. We thus hypothesize that:

HP9. Prior co-creation experience has a positive impact on co-creation interest

\section{Methodology}

\section{Data collection}

In order to test our hypotheses, we conducted a survey among final consumers. We studied co-creation activities in three different industries: sport industry, music industry and manufacturing industry. While most of the scholars have observed co-creation activities in some traditional industries such as automotive, food, fashion and semiconductors, we selected these industries as they are fast growing ones, which an increasing number of passionate consumers. Hence, they can benefit from co-creation strategies development. Moreover, we 
decided to investigate three industries with distinct underlying characteristics, to discern potential differences in co-creation levers. We proposed a specific product in each industry, namely fitness tracker for the sport industry, MP3 player for the music industry and 3D printing for the manufacturing industry. In the first section of the survey, subjects answered to questions related to their personality traits, which helped us to classify them in different cocreator typologies, as defined by prior literature. In the second section, consumer knowledge and prior co-creation activity in the field have been assessed, together with motivations and inhibitors for participating in co-creation. Finally, consumer interest and inclination toward using co-creation tools have been investigated. The surveys have been distributed to the general public, through virtual communities' websites, social networks, Universities and international company websites. We received 563 responses. After deletion of missing, incomplete and invalid responses, we obtained a valid dataset of 509 answers. Demographic statistics are provided in Appendix 1.

\section{Measurements}

All constructs were adapted from prior literature. We measured motivations, inhibitors and personality traits using 7 point Likert scales, anchored by 7 as strongly agree and 1 as strongly disagree. Product knowledge items were following a 5 point Likert scale where 5 is anchored to strongly agree and 1 to strongly disagree. Interest in co-creation, co-creation tool preference and prior co-creation experience consisted of a yes/no question. To measure the innovator personal traits the scale of Agarwal \& Prasad (1998) has been employed. Market maven traits were measured adopting Feick \& Price (1987) scale, emergent nature traits have been measured through Hoffman et al (2009) scale. The technology optimism and technology innovativeness constructs have been employed to capture the technology enthusiastic consumers (Magnusson, 2009). Regarding motivations, we employed Sun, Fang, \& Lim (2012) scale to measure monetary motivations. All other motivation scales were adapted from 
Nambisan \& Baron (2007). Discredit and effort inhibitors were measured through

Kankanhalli et al. (2005) scales. Finally, product knowledge consists of three items which evaluate the self-assessment of consumers' knowledge about the products and has been measured using Schreier \& Prügl (2008) scale.

\section{Results}

The research model for this study required three steps of analyses, following constructs reliability assessment. First of all, we assessed reliability of scales. Secondly, we conducted multiple t-test of independence to analyze the extent to which motivations and inhibitors are affected by consumers' personal traits. Thirdly, we assessed the association between a peculiar personal trait and preference for a specific co-creation tool through a Chi-square test of independence. Finally, we performed a binary logistic regression to analyze the impact of motivations and inhibitors and of product-related drivers on interest to co-create.

\section{Reliability assessment}

Scale reliability for personality traits, motivations, inhibitors and product knowledge constructs was examined, through Cronbach's alpha. A satisfactory value was obtained for all the constructs, supporting their internal consistency. Table 1 presents descriptive statistics, reliability and correlations for all measures included in the study. 


\begin{tabular}{|c|c|c|c|c|c|c|c|c|c|c|c|c|c|c|c|c|}
\hline & Mean & St Dev & Reliab. & n. items & 1 & 2 & 3 & 4 & 5 & 6 & 7 & 8 & 9 & 10 & 11 & 12 \\
\hline 1. Innovator & 5.09 & 1.24 & .817 & 3 & 1 & $.606^{* *}$ & $.595^{* *}$ & $.643^{* *}$ & $.207^{* *}$ & $.216^{* *}$ & $.192^{* *}$ & $.139^{* *}$ & .084 & -.044 & -.048 & $.343^{* *}$ \\
\hline 2. Market_mav & 4.97 & 1.28 & .906 & 5 & & 1 & $.510^{* *}$ & $.566^{* *}$ & $.245^{* *}$ & $.217^{* *}$ & $.233^{* *}$ & $.210^{* *}$ & $.126^{* *}$ & .032 & -.029 & $.326^{* *}$ \\
\hline 3. Emergent_nat & 5.07 & .98 & .893 & 8 & & & 1 & $.599^{* *}$ & $.366^{* *}$ & $.306^{* *}$ & $.367^{* *}$ & $.229^{* *}$ & $.165^{* *}$ & -.034 & -.009 & $.370^{* *}$ \\
\hline 4. Technology_en & 4.96 & 1.03 & .784 & 6 & & & & 1 & $.251^{* *}$ & $.267^{* *}$ & $.305^{* *}$ & $.192^{* *}$ & $.139^{* *}$ & -.034 & -.036 & $.400^{* *}$ \\
\hline 5. Mot_learn & 5.33 & .98 & .826 & 3 & & & & & 1 & $.466^{* *}$ & $.459^{* *}$ & $.264^{* *}$ & $.192^{* *}$ & $-.169^{* *}$ & -.004 & $.242^{* *}$ \\
\hline 6. Mot_social & 4.94 & 1.12 & .752 & 2 & & & & & & 1 & $.539^{* *}$ & $.287^{* *}$ & $.273^{* *}$ & .017 & .000 & $.200^{* *}$ \\
\hline 7. Mot_personal & 4.71 & 1.04 & .824 & 4 & & & & & & & 1 & $.325^{* *}$ & $.390^{* *}$ & .054 & $.107^{*}$ & $.239^{* *}$ \\
\hline 8. Mot_hedonic & 4.85 & 1.18 & .866 & 3 & & & & & & & & 1 & $.240^{* *}$ & $.090^{*}$ & .061 & $.175^{* *}$ \\
\hline 9. Mot_monetary & 4.38 & 1.31 & .863 & 3 & & & & & & & & & 1 & $.214^{* *}$ & $.218^{* *}$ & $.090^{*}$ \\
\hline 10. In_effort & 3.85 & 1.06 & .895 & 3 & & & & & & & & & & 1 & $.426^{* *}$ & -.047 \\
\hline 11. In_risk & 2.96 & 1.17 & .764 & 4 & & & & & & & & & & & 1 & .011 \\
\hline 12. Pdt_know & 4.51 & 1.27 & .708 & 3 & & & & & & & & & & & & 1 \\
\hline
\end{tabular}

\section{T-test of independence}

To examine the impact of the co-creator typology (innovator, market maven, emergent nature and technology enthusiast consumer) on perceived motivations and inhibitors to co-create we performed multiple T-tests. We averaged across items obtaining a single value for each construct and divide consumer in two groups, high versus low in the specific personality trait, based on the sample mean.

Results of t-test (Table 2) show that innovators have significantly higher learning motivations, social motivations, personal motivations and higher hedonic motivations than low innovative individuals, thus partially confirming H2.1. Innovators did not show a significantly lower level of perceived constraints thus not confirming H2.2. Market mavens, emergent nature consumers and technology enthusiastic consumers perceived higher learning, social, personal, hedonic and monetary motivations than consumers low in the respective traits thus confirming H3.1, H4.1 and H5.1. However, risk and energy inhibitors were not significantly lower for market mavens and technology enthusiastic consumers, thus not 
confirming H3.2 and H5.2. Emergent nature consumers were the only segment showing to be significantly lower in risk inhibitors but not on effort inhibitor, thus only partially confirming H4.2.

Table 2. T-tests results

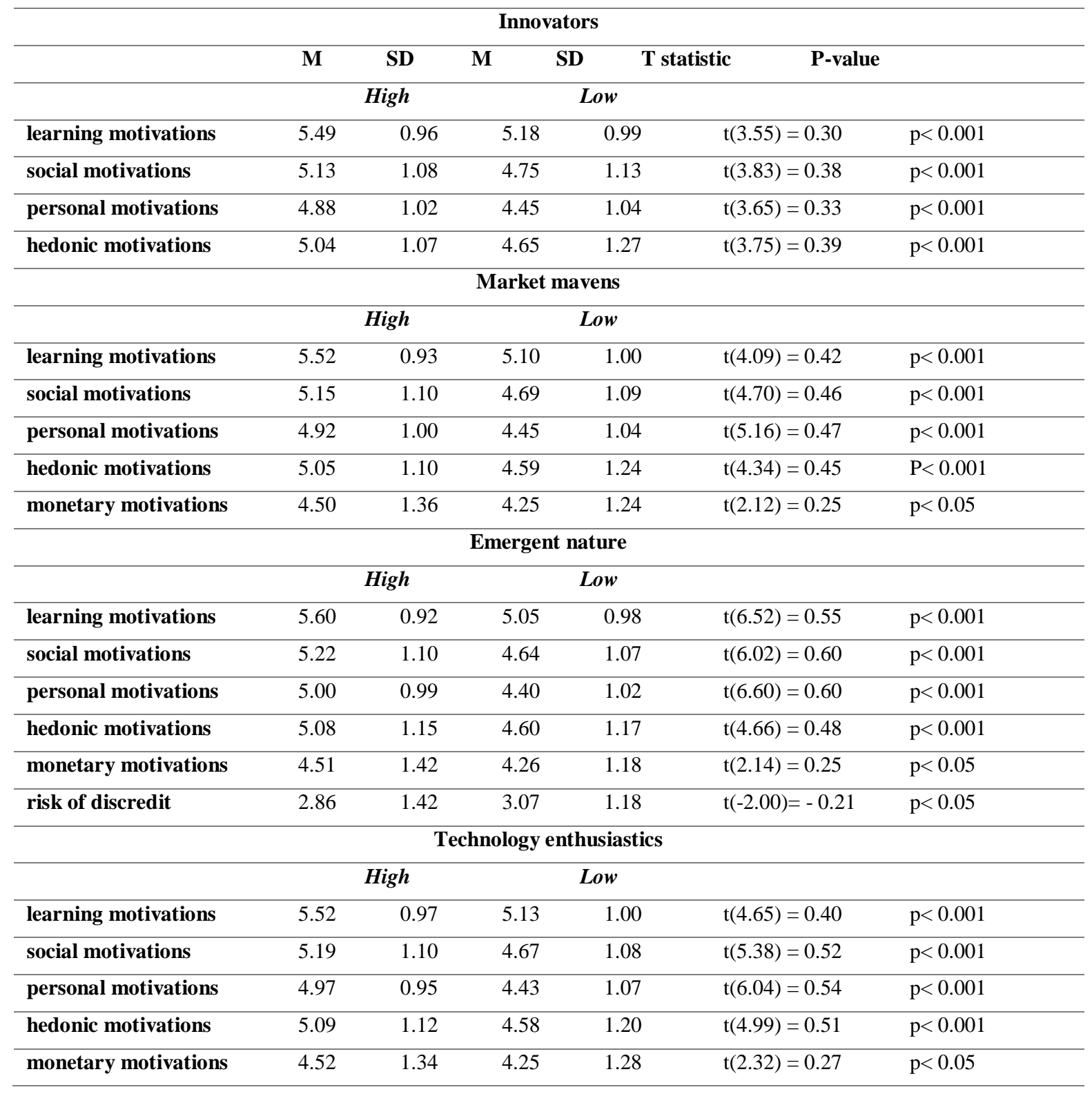

\section{Chi-Square test of association}

A Chi-square test of association has been conducted to assess the relation between personality traits and preference for a specific co-creation tool. Table 3 reports the results of the test. We observed a strong association between co-creation communities' preference and emergent 
nature $(\chi 2(1)=11,648, p<.001)$ and technology enthusiastic consumers $(\chi 2(1)=4,427$, $\mathrm{p}<.05)$. Regarding toolkits for user innovation, innovators $(\chi 2(1)=4,775, \mathrm{p}<.05)$, emergent nature consumers $(\chi 2(1)=11,19, \mathrm{p}<.001)$ and technology enthusiastic $(\chi 2(1)=4,934, \mathrm{p}<.05)$ showed a preference for this tool. Ideation contest emerged as positively associated with emergent nature traits $(\chi 2(1)=9,488, \mathrm{p}<.01)$ and technology enthusiastic personality $(\chi 2(1)=$ $4,589, \mathrm{p}<.05)$ while workshops preference is associated with market mavens $(\chi 2(1)=8,062$, $\mathrm{p}<.01)$, emergent nature $(\chi 2(1)=14,408, \mathrm{p}<.001)$ and technology enthusiastic traits $(\chi 2(1)=$ $4,129, \mathrm{p}<.05)$.

Results supported most of our hypotheses. HP6.1 has been partially confirmed as innovators showed a preference toward toolkits for user innovation but did not show a significant association with ideation contest. Results confirmed that market mavens have a preference for workshops but no significant association has been found for co-creator communities (this partially confirming HP6.2). HP6.3 and HP6.4 are confirmed: emergent nature and technology enthusiastic consumers showed a positive association to all co-creation tools, namely co-creation communities, toolkits for user innovation, ideation contests and workshops.

Table 3. Chi-square test results

\begin{tabular}{|c|c|c|c|c|c|c|c|c|c|c|c|c|c|}
\hline \multicolumn{2}{|c|}{ Tool preference } & \multicolumn{3}{|c|}{ Innovator } & \multicolumn{3}{|c|}{ Market maven } & \multicolumn{3}{|c|}{ Emergent nature } & \multicolumn{3}{|c|}{ Technology enthusiastic } \\
\hline & &, 00 & $\mathbf{1 , 0 0}$ & $\chi^{2}$ &, 00 & $\mathbf{1 , 0 0}$ & $\chi^{2}$ &, 00 & $\mathbf{1 , 0 0}$ & $\chi^{2}$ &, 00 & $\mathbf{1 , 0 0}$ & $\chi^{2}$ \\
\hline Co-creation & Unlikely to use & $49,7 \%$ & $50,3 \%$ & n.s. & $45,7 \%$ & $54,3 \%$ & n.s. & $53,4 \%$ & $46,6 \%$ & $11,648^{* *}$ & $50,6 \%$ & $49,4 \%$ & $4,427^{*}$ \\
\hline communities & Likely to use & $47,0 \%$ & $53,0 \%$ & & $39,2 \%$ & $60,8 \%$ & & $37,6 \%$ & $62,4 \%$ & & $40,9 \%$ & $59,1 \%$ & \\
\hline Toolkits for & Unlikely to use & $52,3 \%$ & $47,7 \%$ & $4,775^{*}$ & $45,6 \%$ & $54,4 \%$ & n.s. & $53,2 \%$ & $46,8 \%$ & $11,19^{* *}$ & $50,8 \%$ & $49,2 \%$ & $4,934^{*}$ \\
\hline user innovation & Likely to use & $42,1 \%$ & $57,9 \%$ & & $39,3 \%$ & $60,7 \%$ & & $37,6 \%$ & $62,4 \%$ & & $40,4 \%$ & $59,6 \%$ & \\
\hline Ideation & Unlikely to use & $51,4 \%$ & $48,6 \%$ & n.s. & $44,9 \%$ & $55,1 \%$ & n.s & $53,0 \%$ & $47,0 \%$ & $9,488^{* *}$ & $50,8 \%$ & $49,2 \%$ & $4,589^{*}$ \\
\hline contest & Likely to use & $44,1 \%$ & $55,9 \%$ & & $41,0 \%$ & $59,0 \%$ & & $38,8 \%$ & $61,2 \%$ & & $41,0 \%$ & $59,0 \%$ & \\
\hline \multirow[t]{2}{*}{ Workshops } & Unlikely to use & $50,4 \%$ & $49,6 \%$ & n.s. & $47,2 \%$ & $52,8 \%$ & $8,062 * *$ & $52,8 \%$ & $47,2 \%$ & 14 & $49,9 \%$ & $50,1 \%$ & $4,129^{*}$ \\
\hline & Likely to use & $44,1 \%$ & $55,9 \%$ & & $33,1 \%$ & $66,9 \%$ & & $33,8 \%$ & $66,2 \%$ & $408 * *$ & $39,7 \%$ & $60,3 \%$ & \\
\hline
\end{tabular}




\section{Binary logistic regression}

Finally, a binary logistic regression was used to test the relationship between interest to participate in co-creation activity, personality related drivers (motivations and inhibitors) and product-related drivers (product typology, product knowledge and prior co-creation experience with the product). Table 4 shows the results of the regression analysis.

\section{Table 4. Binary logistic regression results}

\begin{tabular}{|c|c|c|c|c|c|c|}
\hline Independent variable & $B$ & $S E$ & Wald & $d f$ & p-value & $\operatorname{Exp}(B)$ \\
\hline Learning motivations & .236 & .142 & 2.774 & 1 & .096 & 1.267 \\
\hline Social motivations & -.165 & .138 & 1.442 & 1 & .230 & .848 \\
\hline Personal motivations & .374 & .146 & 6.577 & 1 & .010 & 1.454 \\
\hline Hedonic motivations & .137 & .106 & 1.663 & 1 & .197 & 1.146 \\
\hline Monetary motivations & .206 & .103 & 3.991 & 1 & .046 & 1.229 \\
\hline Risk of discredit & -.050 & .118 & .182 & 1 & .670 & .951 \\
\hline Effort and time inhibitor & -.090 & .129 & .490 & 1 & .484 & .914 \\
\hline Cocreation experience & 1.899 & .540 & 12.381 & 1 & .000 & 6.678 \\
\hline Product knowledge & .274 & .101 & 7.332 & 1 & .007 & 1.316 \\
\hline industry & & & 9.051 & 2 & .011 & \\
\hline industry(sport) & -.870 & .315 & 7.605 & 1 & .006 & .419 \\
\hline industry(music) & -.809 & .310 & 6.816 & 1 & .009 & .445 \\
\hline \multicolumn{7}{|l|}{ Overall model evaluation } \\
\hline & $X$ & $d f$ & p-value & & & \\
\hline Model $\boldsymbol{X}$ & 82.862 & 11 & .000 & & & \\
\hline Hosmer \& Lemeshow & 9.609 & 8 & .294 & & & \\
\hline \multicolumn{7}{|l|}{ Pseudo $R^{2}$} \\
\hline Cox and Snell & .150 & & & & & \\
\hline Nagelkerke R square & .228 & & & & & \\
\hline $\mathbf{N}$ & 509 & & & & & \\
\hline
\end{tabular}

The model shown a good fit to the data $(\chi 2=81.08 d f=11 \mathrm{p}<.001)$. Regarding motivations, we found monetary and personal motivations to have a significant positive effect on interest to co-create confirming HP1.3 and HP1.5. However, we did not find any significant relationships between learning, hedonic and social motivations and for inhibitors thus not 
confirming HP1.1, HP1.2, HP1.4, HP1.6 and HP1.7. Product related drivers are strong and significant predictors of co-creation interest. Co-creation experience, product knowledge and industry have a direct impact on the willingness to co-create of the consumers, thus supporting HP7, HP8 and HP9.

\section{Discussion and implications}

The findings of this study confirm our assumptions and prior research individuating in innovators, market mavens, emergent nature and technology enthusiast consumers proactive targets, willing to involve in co-creation. These consumer segments show higher learning, personal, social and hedonic benefits compared to ordinary consumers, aligned to what has been explored in prior research (Lüthje, 2004). Except innovators, monetary motivations appear to be relevant as well. Neither losing power, fame and knowledge in a community of participants, nor the effort and time-consuming process of co-creation however have been shown as significantly lower than ordinary consumers, except for emergent nature consumers. This typology showed significantly lower perceived risk of discredit, confirming the creativity and openness of this segment (Hoffman et al., 2009). Thus, results confirmed that the consumer segments investigated perceive higher motivations than ordinary consumers, above providing better ideas and innovative outcomes to firms when they are involved (Hoyer et al., 2010) but did not show lower sensibility to inhibitors as we expected. This is a relevant result for firms that should, above improving consumer benefits, also reduce inhibitors that seem to affect consumer segments more apt to co-create. The finding that monetary motivations are greater for these segments also suggests that, contrary to prior research (Füller, 2010), not only consumers with lower intrinsic motivations are attracted by monetary rewards but also the ones who are motivated by intrinsic benefits.

Secondly, our analyses show that, regardless the typology of consumers, personal and monetary motivations are the ones that significantly determine interest to participate in co- 
creation. Hence, even if consumers seem to finally perceive other intrinsic motivations from this activity, what spurs them to initially involve in co-creation are tangible benefits, such as personal and financial rewards. We believe this is an extremely interesting result for firms as it shows that the way to initially attract co-creators is to provide them clear incentives, a tangible added value for their effort and time. Together with these motivations, the product typology, consumer knowledge and prior co-creation experience, have been shown as relevant drivers of interest confirming prior research (Etgar, 2008; Fuller et al. 2011) that sustain consumers co-create in product categories they love and in which they feel expert. In this respect, we found that users of $3 \mathrm{D}$ printing get stimulated in joining co-creation more than users active in the music and sport industries. We can speculate that the additive manufacturing field, being new and fast-growing, is more attractive and rewarding than music and sport industries and thus attracts more potential co-creators. To motivate consumers in initially joining co-creation activities, firms should provide them the tools they are more apt to use. Our findings suggest that different consumer segments have different preferences regarding co-creation tools. Consumers characterized by relevant social attitudes, such as market mavens, are more willing to participate in workshops, while innovators have a preference for toolkits for user innovation, better answering to their creativity needs. Emergent nature, being defined as eclectic consumers, show a generalized predisposition to all co-creation methods compared to ordinary consumers. The same is true for technology enthusiast consumers that showed a generalized openness to all co-creation tools.

To summarize, four steps are suggested to Companies that want to effectively and efficiently develop co-creation activities: (1) find consumers who are active promoter of the product/brand or at least that show to like it (e.g. on social media); (2) attract these consumers by providing them clear incentives, especially monetary and personal rewards that demonstrate to be effective in attracting co-creators; (3) tailor following communication with 
multiple appeals. For instance, a fun innovation contest can elicit different motivations: hedonic (fun), monetary and personal (possibility to win the contest), social (community involvement) and learning (access to new information and knowledge enhancement); (4) tailor co-creation tools to the consumer segments the product attracts.

\section{Conclusions and future research}

The aim of this research is to deepen current knowledge on consumer co-creation levers by investigating the personal and the product related drivers of interest. Further, this work wants to shed lights on the influence of personality traits on preferred co-creation tools, motivations and inhibitors. We investigated five kinds of motivations, founded in extant literature: monetary motivations, namely financial rewards to participation, hedonic motivations, representing the fun and enjoyment derived from the co-creation activity, learning motivations deriving from knowledge seeking behaviors and consumer curiosity and social motivations, defined as the desire to be in contact with like-minded people and enhance one's social status. Two were the inhibitors analyzed: effort, in terms of time and energy, required to participate in co-creation and risk of discredit. We analyzed four consumer segments: innovators, emergent nature, market mavens and technology enthusiast consumers. Finally, four co-creation tools were explored: workshops, communities, toolkits for user innovation and contests. Results showed that personality traits affect preferred co-creation tools and motivations but exert few influence on inhibitors to co-create. Further, personal and monetary motivations, together with product-related drivers have been confirmed as significant predictor of interest to co-create.

Future research is needed to deepen these findings. This work analyzes co-creation interest in three industries but further fields may be analyzed to generalize our findings and provide insights and guidance to practitioners. Considering the fast development of co- 
creation projects across different industries, indeed, a deeper understanding of industries specificities may be helpful for companies while developing such activities. Our research focuses on the initial phase in which consumers are approached by the company. However, the change in predominant motivations along the co-creation process is an interesting area of research, that can help companies in modulating benefits along the new product development process, providing the most relevant ones for each stage. Complementary to such analysis, it would be interesting to investigate the potential change in co-creator segments along the NPD process, thus if a certain consumer segment is more willing to participate into a specific phase of the co-creation process. This would help firms in providing the right incentives and tools at each stage of the process.

Acknowledgement. Our sincere thanks are due to the three Companies which helped us distributing the questionnaires to the final consumers. We would particularly like to thank the management team of www.fitnessmagazine.ir, www.ebee.ir and www.anjammidam.com who agreed eagerly for contributing to our research.

\section{References}

Aarikka-Stenroos, L., \& Jaakkola, E. (2012). Value co-creation in knowledge intensive business services: A dyadic perspective on the joint problem solving process. Industrial Marketing Management, 41(1), 15-26.

Agarwal, R., \& Prasad, J. (1998). A Conceptual and Operational Definition of Personal Innovativeness in the Domain of Information Technology. Information Systems Research, 9(2), 204-215.

Alba, J. W., \& Hutchinson, J. W. (1987). Dimensions of Consumer Expertise. Journal of Consumer Research, 13(4), 411. 
Atkin, C. K. (1972). Anticipated Communication and Mass Media Information-Seeking. The Public Opinion Quarterly, 36(2), 188-199.

Bagozzi, R. P. (1981). Attitudes, Intentions , and Behavior : A Test of Some Key Hypotheses. Journal of Personality and Social Psychology, 41(4), 607-627.

Bettiga, D., \& Lamberti, L. (2017). Exploring the adoption process of personal technologies: A cognitive-affective approach. Journal of High Technology Management Research, 28(2), 179-187.

Blumler, J. G., \& Katz, E. (1974). The Uses of mass communications: current perspectives on gratifications research, Volume 1974, Part 1. Sage Publications.

Bugshan, H. (2015). Co-innovation: the role of online communities. Journal of Strategic Marketing. Ournal of Strategic Marketing, 23(2), 175-186.

Bullinger, A. C., Neyer, A.-K., Rass, M., \& Moeslein, K. M. (2010). Community-Based Innovation Contests: Where Competition Meets Cooperation. Creativity and Innovation Management, 19(3), 290-303.

Cordell, V. V. (1997). Consumer knowledge measures as predictors in product evaluation. Psychology and Marketing, 14(3), 241-260.

Etgar, M. (2008). A descriptive model of the consumer co-production process. Journal of the Academy of Marketing Science, 36(1), 97-108.

Feick, L. F., \& Price, L. L. (1987). The Market Maven: A Diffuser of Marketplace Information. Journal of Marketing, 51(1), 83.

Fernandes, T., \& Remelhe, P. (2016). How to engage customers in co-creation: customers' motivations for collaborative innovation. Journal of Strategic Marketing, 24(3-4), 311326.

Franke, N., \& Shah, S. (2011). How Communities Support Innovative Activities : An 
Exploration of Assistance and Sharing Among End-Users, 1-47.

Fredberg, T., \& Piller, F. T. (2011). The paradox of tie strength in customer relationships for innovation: a longitudinal case study in the sports industry. $R \& D$ Management, $41(5)$, $470-484$.

Füller, J. (2010). Refining Virtual Co-Creation from a Consumer Perspective. California Management Review, 52(2), 98-122.

Füller, J., Hutter, K., \& Faullant, R. (2011). Why co-creation experience matters? Creative experience and its impact on t... R\&D Management, 41(3), 259-273.

Fuller, J., Kurt, M., \& Hopper, M. (2008). Brand Community Mebers as a Source of Innovation. The Journal of Product Innovation Management, 25, 608-619.

Füller, J., Mühlbacher, H., Matzler, K., \& Jawecki, G. (2009). Consumer Empowerment Through Internet-Based Co-creation. Journal of Management Information Systems, 26(3), 71-102.

Gebauer, J., Füller, J., \& Pezzei, R. (2013). The dark and the bright side of co-creation: Triggers of member behavior in online innovation communities. Journal of Business Research, 66(9), 1516-1527.

Haythornthwaite, C. (2008). Learning relations and networks in web-based communities. Int. J. Web Based Communities, 4(2), 140-158.

Heidenreich, S., \& Handrich, M. (2015). Adoption of technology-based services: the role of customers' willingness to co-create. Journal of Service Management, 26(1), 44-71.

Hienerth, C., Lettl, C., \& Keinz, P. (2013). Synergies among Producer Firms, Lead Users, and User Communities: The Case of the LEGO Producer-User Ecosystem. Journal of Product Innovation Management, 31(4).

Hienerth, C., Poetz, M., \& von Hippel, E. (2007). Exploring key characteristics of lead user 
workshop participants: who contributes best to the generation of truly novel solutions. In Proc. of the DRUID Summer Conference 2007 on Appropriability, Proximity, Routines and Innovation., 1-32.

Hirschman, E. C. (1980). Innovativeness, Novelty Seeking, and Consumer Creativity. Journal of Consumer Research, 7(3), 283.

Hoffman, D. L., Kopalle, P. K., \& Novak, T. P. (2009). The "Right" Consumers for Better Concepts - Identifying and Using Consumers High in Emergent Nature to Further Develop New Product Concepts, 1-52.

Hoyer, W. D., Chandy, R., Dorotic, M., Krafft, M., \& Singh, S. S. (2010). Consumer Cocreation in New Product Development. Journal of Service Research, 13(3), 283-296.

Hutter, K., Hautz, J., Füller, J., Mueller, J., \& Matzler, K. (2011). Communitition: The Tension between Competition and Collaboration in Community-Based Design Contests. Creativity and Innovation Management, 20(1), 3-21.

Kankanhalli, A., Tan, B. C. Y., \& Wei, K. (2005). Contributing knowledge to electronic knowledge repositories: An empirical investigation, 29(1), 113-143.

Kassarjian, H. (1981). Low Involvement: A Second Look. In NA - Advances in Consumer Research Volume 08, Eds. Kent B. Monroe, Ann Abor, MI : Association for Consumer Research, 31-34.

Kirton, M. (1976). Adaptors and innovators: A description and measure. Journal of Applied Psychology, 61(5), 622-629.

Lerner, J., \& Tirole, J. (2001). The open source movement: Key research questions. European Economic Review, 45(4-6), 819-826.

Levy, M. R. (1978). Opinion Leadership and Television News Uses. Public Opinion Quarterly, 42(3), 402. 
Lilien, G. L., Morrison, P. D., Searls, K., Sonnack, M., \& Hippel, E. von. (2002).

Performance Assessment of the Lead User Idea-Generation Process for New Product Development. Management Science, 48(8), 1042-1059.

Lüthje, C. (2004). Characteristics of innovating users in a consumer goods field. Technovation, 24(9), 683-695.

Magnusson, P. R. (2009). Exploring the Contributions of Involving Ordinary Users in Ideation of Technology-Based Services. Journal of Product Innovation Management, 26(5), 578-593.

Martini, A., Massa, S., \& Testa, S. (2014). Customer co-creation projects and social media: The case of Barilla of Italy. Business Horizons, 57(3), 425-434.

McAlexander, J. H., Schouten, J. W., \& Koenig, H. F. (2002). Building Brand Community. Journal of Marketing, 66(1), 38-54.

Moore, G. A., \& McKenna, R. (1999). Crossing the Chasm: Marketing and Selling High-Tech Products to Mainstream Customers. HarperBusiness. New York.

Muniz, A. M., \& O’Guinn, T. C. (2001). Brand Community. Journal of Consumer Research, 27(4), 412-432.

Nambisan, S., \& Baron, R. a. (2007). Interactions in virtual customer environments: Implications for product support and customer relationship management. Journal of Interactive Marketing, 21(2), 42-62.

Parasuraman, A. (2000). Technology Readiness Index (Tri): A Multiple-Item Scale to Measure Readiness to Embrace New Technologies. Journal of Service Research, 2(4), $307-320$.

Paulini, M., Maher, M. Lou, \& Murty, P. (2014). Motivating participation in online innovation communities. International Journal of Web Based Communities, 10(1), 94. 
Piller, F., Vossen, A., \& Ihl, C. (2012). From Social Media to Social Product Development: The Impact of Social Media on Co-Creation of Innovation. Die Unternehmung, 66(1), 727.

Piller, F., \& Walcher, D. (2006). Toolkits for idea competitions: a novel method to integrate users in new product development. $R$ and D Management, 36(3), 307-318.

Prahalad, C. K., \& Ramaswamy, V. (2004a). Co-creating unique value with customers. Strategy \& Leadership, 32(3), 4-9.

Prahalad, C. K., \& Ramaswamy, V. (2004b). Co-creation experiences: The next practice in value creation. Journal of Interactive Marketing, 18(3), 5-14.

Prugl, R., \& Schreier, M. (2006). Learning from leading-edge customers at The Sims: opening up the innovation process using toolkits. $R$ and $D$ Management, 36(3), 237-250.

Rogers, E. M. (2010). Diffusion of innovations. Simon and Schuster.

Roser, T., Samson, A., Cruz-Valdivieso, E., \& Humphreys, P. (2009). Co-creation : New pathways to value An overview. Promise Corporation, 22.

Schreier, M., \& Prügl, R. (2008). Extending lead-user theory: Antecedents and consequences of consumers' lead userness. Journal of Product Innovation Management, 25(4), 331346.

Schuhmacher, M. C., \& Kuester, S. (2012). Identification of Lead User Characteristics Driving the Quality of Service Innovation Ideas. Creativity and Innovation Management, 21(4), 427-442.

Shah, S. (2000). Sources and Patterns of Innovation in a Consumer Products Field: Innovations in Sporting Equipment. Sloan Working Paper, (4105), 1-27.

Sieber, S. D. (1974). Toward a Theory of Role Accumulation. American Sociological Review, 39(4), 567. 
Slama, M., \& Tashchian, A. (1985). Selected socioeconomic and demographic characteristics associated with purchasing involvement. Journal of Marketing, 49(1), 72-82.

Summary, A., \& Reading, F. (2002). Customers as Innovators: ANew Way to Create Value. Harvard Business Review, 80(4), 74-81.

Sun, Y., Fang, Y., \& Lim, K. H. (2012). Understanding sustained participation in transactional virtual communities. Decision Support Systems, 53(1), 12-22.

Taghizadeh, S. K., Rahman, S. A., \& Marimuthu, M. (2018). Idea generation leveraged from value co-creation process enhances new service development performance. Journal of Strategic Marketing, 1-22.

Tsikriktsis, N. (2004). A Technology Readiness-Based Taxonomy of Customers A Replication and Extension. Journal of Service Research, 7(1), 42-52.

von Hippel, E. (1986). Lead Users: A Source of Novel Product Concepts. Management Science, 32(7), 791-805.

von Hippel, E. (2005). Democratizing innovation: The evolving phenomenon of user innovation, 55(1), 63-78.

Von Hippel, E. (2001). Learning from open-source software. MIT Sloan Management Review.

Von Hippel, E. (2007). The sources of innovation. Das Summa Summarum Des Management. Gabler, 111-120.

von Hippel, E., \& Katz, R. (2002). Shifting Innovation to Users via Toolkits. Management Science, 48(7), 821-833.

Wasko, M., \& Faraj, S. (2000). It is what one does: why people participate and help others in electronic communities of practice. Journal of Strategic Information Systems. 
Appendix 1. Demographic Statistics ${ }^{a}$

\begin{tabular}{lll}
\hline Industry & & $\%$ \\
\hline & Additive manufacturing & 34.8 \\
\hline Gender & Music & 34 \\
\hline & Female & 31.2 \\
\hline Age & Male & 71.5 \\
\hline \multirow{2}{*}{ Education } & $<30$ years old & 28.5 \\
\hline \multirow{2}{*}{ Co-creation experience } & No years old & 78.6 \\
\hline & High School & 21.4 \\
\hline & Bachelor degree & 3.7 \\
\hline Willingness to co-create & No & 23.4 \\
\hline & Yaster degree & 61.1 \\
\hline & Yes & 82.3 \\
\hline & & 11.8 \\
\hline
\end{tabular}

aN=509

This is an accepted manuscript of an article published by Taylor \& Francis in Journal of Strategic Marketing on 24 Apr 2018, available online at: 10.1080/0965254X.2018.1464051 